\title{
Study on User-defined Design Based on the Reconstructed Modular Houses After the Earthquake
}

\author{
Xiaojuan Hui \\ Nankai University Binhai College \\ Tianjin, China
}

\author{
Dan Wang \\ Nankai University Binhai College \\ Tianjin, China
}

\begin{abstract}
In recent years, due to the frequent occurrence of earthquakes, great damages have been caused, and reconstruction after the earthquake has become a hot topic for everyone. Reconstruction after the earthquake usually faces problems of time constraints, shortage funds and etc., so that it cannot quickly and effectively meets the housing needs of the affected people. Moreover, the new housing has a single model, which cannot meet the needs of different production and living modes of residents; so through explosion of people's basic requirement for house, understand of the specialty of reconstruction and basic requirement for house after the earthquake, this paper studies various combination forms of modular buildings and single building combination form modules, explores related contents of user-defined. After serious analysis and studies, understand the advantages of modular buildings in every aspect, and provide standard modular space for user-defined. The topic is mainly through the introduction of modular design, and the user-defined house model, hoping to meet the different needs of people after the earthquake, to achieve the diversity of house.
\end{abstract}

Keywords-modular residential houses; combination forms; user-defined; standard modular space

\section{INTRODUCTION}

The Asian earthquake belt is mostly distributed in the mountainous area, so the reconstruction area after earthquake is mostly rural area. Now, reconstruction of residential houses mode is single, appearance of all houses looks the same, and they are distributed to families with different needs, which can't bring convenience to all the residents, to some degree it is a mass of waste. Therefore, this subject mainly studies the user-defined design of modular houses in reconstruction area after the earthquake, which will respectively study the combination forms of the residential houses, connection forms of combination units and standard modular residential houses can be defined by users provided by this design.

From the perspective of application, the traditional construction speed of the reconstruction after the earthquake is relatively slow, but the modular buildings can quickly and effectively solve the house problems of affected people, and provide various combination forms of modules. Putting the connection forms of combination units, it can be expressed in various ways and meets different requirements for residential houses of people by means of user-defined.
From the perspective of society, single house model of reconstructed rural areas cannot meet the requirements for life and production of numerous farmers. Modular buildings of reconstruction can avoid the unicity of the reconstructed residential houses after the earthquake, which will lead the reconstructed new rural area to the sustainable development in the process of accelerating the rural urbanization.

Therefore, in terms of the recent conditions, China is in a period of vigorous development of infrastructure, and there is great potential in the construction market. The traditional construction speed of the reconstruction after the earthquake is relatively slow; house price has been high, which continues to plague residents and governments. Hope to understand more and full of the modular residential houses, and the modular buildings can be confirmed by numerous residents because of its unique advantages so that it can be applied in the reconstructed area and cities after the earthquake through the studies.

\section{RELATED CONCEPT OF MODULAR RESIDENTIAL HOUSES IN RECONSTRUCTION AREA AND USER-DEFINED AFTER THE EARTHQUAKE}

\section{A. Modular Residential Houses}

"Modular buildings", which is also called modular assembly building of space system, is an architect form composed of modular construction. All modules should be prefabricated in the factory. All module components should be both a structural unit and a space unit. The structure unit means that each module has its own structure, which can be independent (just as a square box itself); the space unit means that according to different functional requirements, the modules are divided into different spaces, and different facilities are assembled according to requirements (it is equivalent to equip with the necessary facilities for life in the box). All modules will be transported to the site by transportation equipment and hoisted by hoisting equipment after completion of prefabrication in the factory.

\section{B. Combination Forms}

"Combination", as a noun, means a combination of several parts or individuals; as a verb, means organization or combination. Form means the method and way of talking and doing. Therefore, combination forms in this design mean the way to combine each module into a combination. 


\section{User-defined}

"User-defined" is used in computer science, computing technology, software and other fields, borrowed in "modular residential houses of user-defined design", it means that the user can splice and combine the house to meet his own needs according to his preference, combination form of residential houses can be combined according to his own intention.

\section{Standard Modular Space}

"Standard modular space" refers to the space formed by the combination of standard size modules in study.

\section{EXAMPLE ANALYSIS OF THE RECONSTRUCTION RESIDENTIAL HOUSES AND MODULAR RESIDENTIAL HOUSES AFTER THE EARTHQUAKE}

\section{A. Wenchan's Modular Campus}

This is a semi-permanent building with fire-resistant, coldproof, and shock-resisting properties built by CIMC for Yanmen Township, Wenchuan County, which is the solution to the campus of catering, activities, office and teaching. The total construction area of the campus reaches $3000 \mathrm{~m} 2$, which meets the learning and life needs of more than 1,000 students. It is the unique design of the building that separates the campus from the surrounding movable houses. Each module of space is produced by a completely industrialized standard, which is easy to disassemble and can be recycled. This is a leading new model of international architecture, and it is very suitable for use in disaster areas. On the on hand, due to its short construction period, the entire building was selected from the beginning, and it took less than three months from design to assemble; on the other hand, the building has excellent function of earthquake resistance, wind resistance, cold resistance and fire protection. Because it is to build school, so the height is specially adjusted from the original $2.5 \mathrm{~m}$ to $3.1 \mathrm{~m}$, which is conducive to the classroom ventilation and the lighting, the width of the stairs also has taken into full consideration. The modular teaching area of Yanmen middle school in Wenchuan County, newly built, is mainly for children who are too young to be transferred to the other places in "Fig. 1".

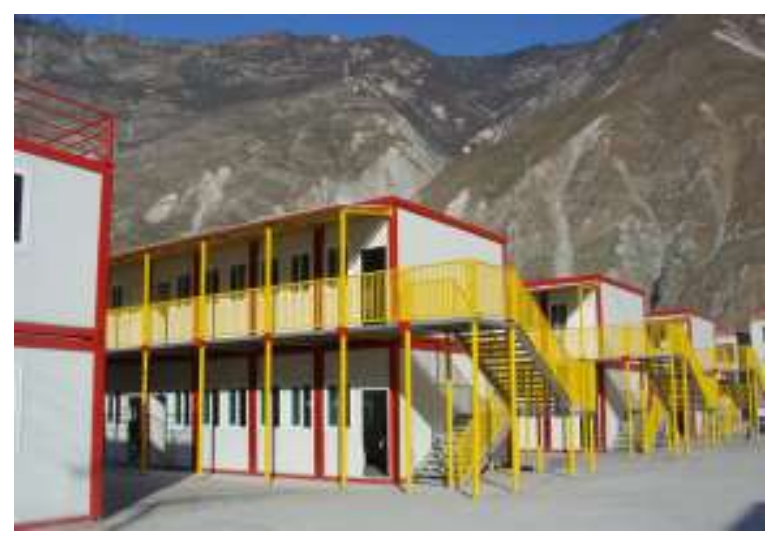

Fig. 1. Wenchuan's modular campus, Source: Baidu picture.

\section{B. Student Apartment at the University of Amsterdam}

In 2006, the student housing in Amsterdam, the Netherlands, was a big problem. Therefore, in order to solve this problem, the government decided to build student apartments in containers. More than 1,000 rooms were built by using containers. Nowadays, container houses are loved by many young people due to their simplicity, economy and practicality. Therefore, container houses are widely used in Amsterdam and many countries and regions around the world. For a long time, the housing problems of low-income people and students have plagued Amsterdam, and the urban population continues to grow, and government pressure continues to increase. In order to plan the internal use of the building, the interior space of these buildings is particularly compact in "Fig. 2".

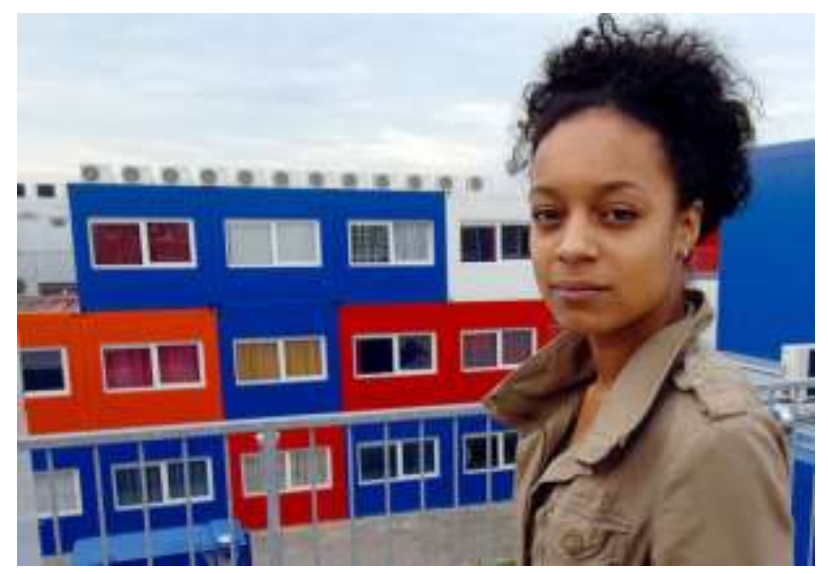

Fig. 2. Student apartment at the University of Amsterdam, student standing before the container buildings, Source: Baidu picture.

The interior space planning of the container is very reasonable. Household items such as sofas, beds, TVs, tables, etc. are complete. In Amsterdam, the Netherlands, container houses are being used more and more. In addition to student apartments, many low-income people also rely on such houses in "Fig. 3".

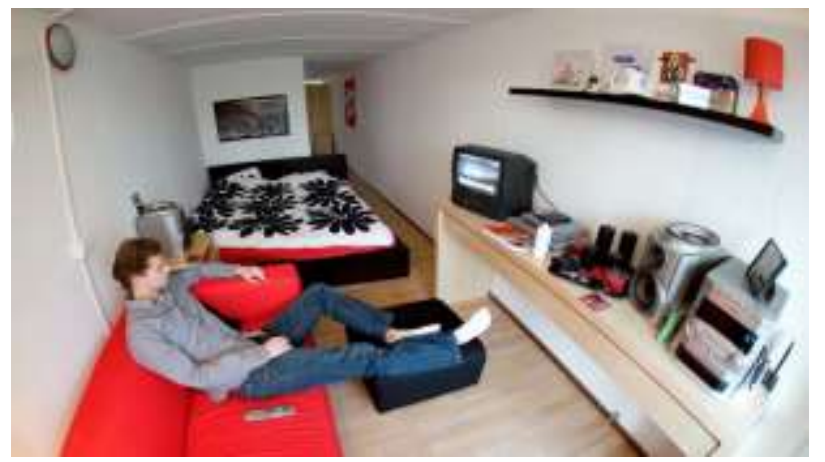

Fig. 3. Student apartment at the University of Amsterdam, Source: Baidu picture.

Container houses are fast and convenient when transporting, because the size and specification of the box are the same. The building process is also many times faster than the common building. The new student apartments in University of Amsterdam are all container buildings (Fig. 4). 


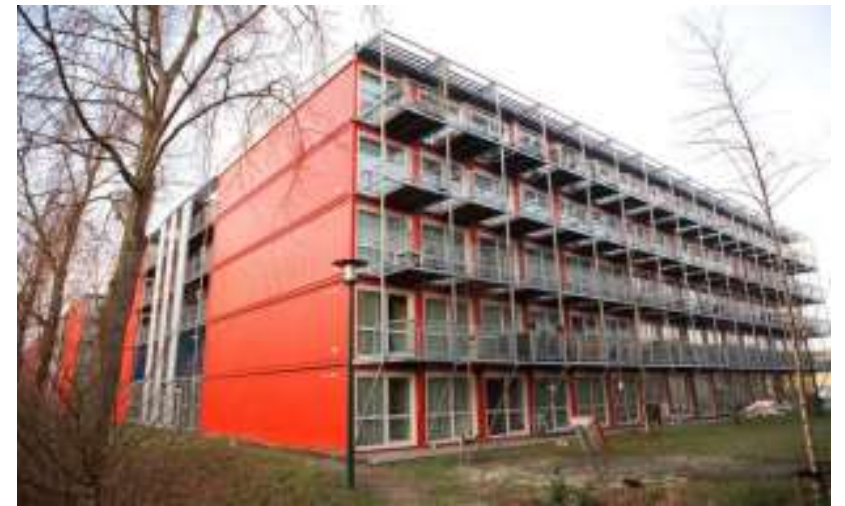

Fig. 4. Student apartment at the University of Amsterdam, Source: Baidu picture.

The container size is internationally regulated, with a length of $12 \mathrm{~m}$, a width of $2.4 \mathrm{~m}$, and a height of $2.6 \mathrm{~m}$. Of course, some containers are not standard size, and some can be up to $2.8 \sim 2.9 \mathrm{~m}$. These containers only need a little maintenance and decoration to be able to live, and can be built like building blocks.

\section{Japanese Cluster Residential House --- Zhongyin Capsule Tower}

The representative works of Kurokawa Kisho --- the implementation process of the Zhongyin Capsule Tower was collaboration between the designer Kurokawa Kisho and the container manufacturer. The building components were all prefabricated at the factory, and they were assembled on site, and all homes were unitized, accommodated in a warehouse with a cabin size of $2.3 \times 2.1 \times 3.8 \mathrm{~m}$. In addition to the most basic stairs in the entire building, there are elevators and other mechanical equipment. The windows of the building are all round, so it is called the "nest box". The building unit is interspersed with the composition, which is very enlightening and has an impact on the Japanese traditional wooden structure in "Fig. 5".

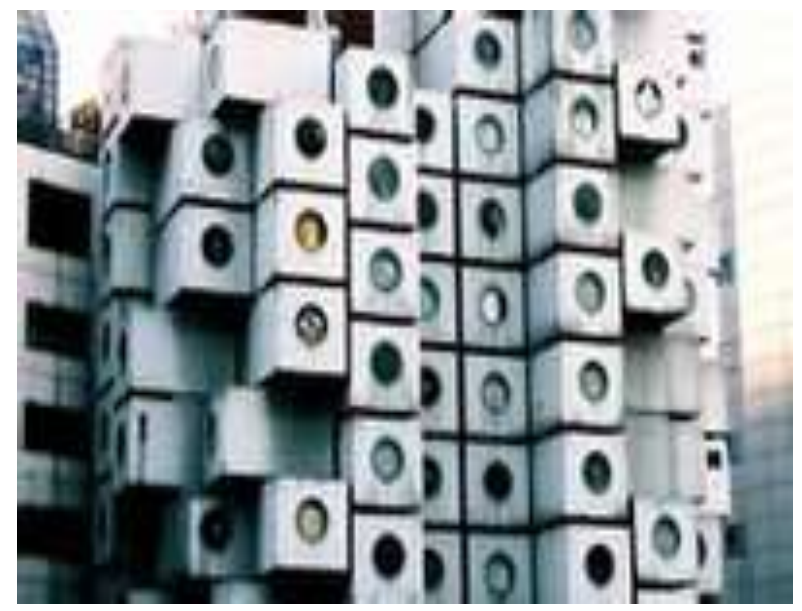

Fig. 5. Zhongyin Capsule Tower, Source: Baidu picture.

With total 140 cabins, the dare and free conception of the designer make the appearance of the building casual, messy but aesthetic. Each cabin is hoisted by the crane and then install next. The details of the window are exquisite, so in terms of the building as a whole, its manufacturing process is quite elaborate. The unique design of doors and windows makes people feel insolation; so many people say that the building is not like residential houses, but a hotel in "Fig. 6" and "Fig. 7".

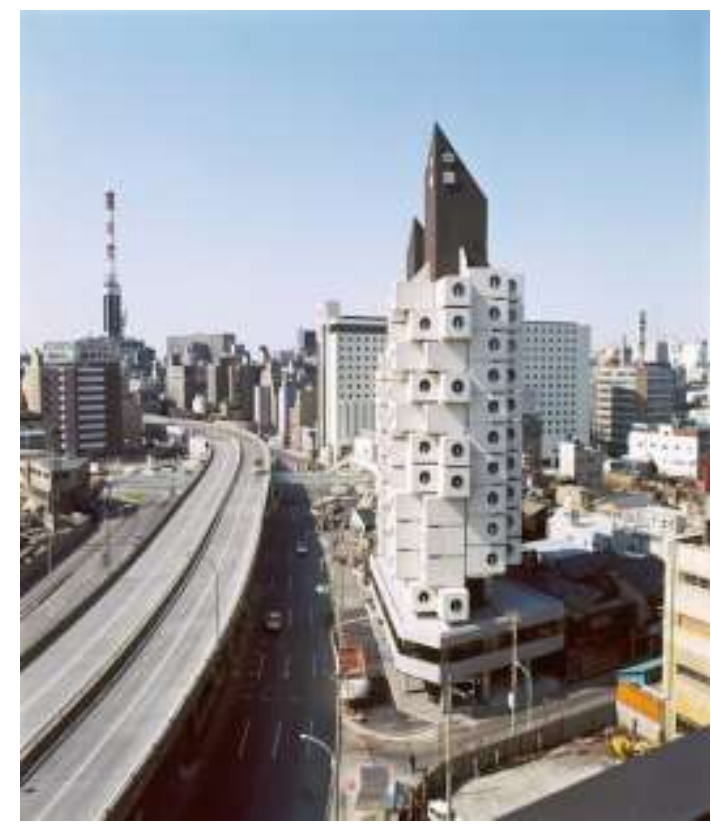

Fig. 6. Zhongyin Capsule Tower, Source: Baidu picture.

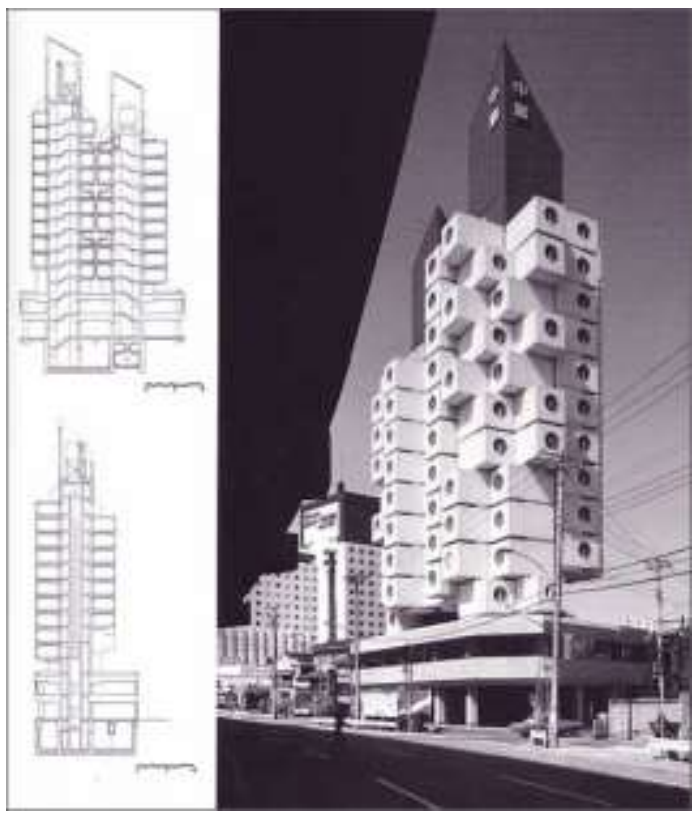

Fig. 7. Zhongyin Capsule Tower, Source: Baidu picture.

\section{Analysis and Conclusion of the Examples}

Wenchuan's modular campus buildings, from the overall perspective, each of them is in the same size, and there are intervals, regular distribution, so we can sum up the whole building unit body as a parallel combination of models; then observing every single building, it is two storeys, and the two storeys are composed of small module in the same size, so we 
can regard this single building as a building made up of two large modules, so it's combination form is coincidence. The modular student apartment at the University of Amsterdam is a large, clustered building. From the facade perspective, it is a regular grid, so the combination form of the building is a cluster structure. Zhongyin Capsule Tower designed by Kurokawa Kisho is a classic cluster building, and its shape is like a grid, with strong sense of concavo-convex from the facade perspective, thus the combination form of the whole building is an irregular grid cluster building.

From the comparison of domestic and foreign modular building cases, the domestic modular building has not yet been vigorously developed. There are still relatively a few existing modular buildings, and relatively speaking, the architectural form is relatively simple and relatively conservative; the population in China is very large, with the increasing of the goods price, the price of the house has been rising and many people cannot afford it; the modular housing cost is low, the occupancy time is fast, and has the anti-cold and anti-shock fire protection, the manpower and material resources are convenient and the price is low, but the development is not very fast in China. In contrast, the foreign manpower and material resources are very expensive, but the modular building is developing better, the architectural form is diversified, the color application is bold, and the public recognition is high.

\section{RESEARCH ON USER-DEFINED DESIGN OF MODULAR HOUSES IN RECONSTRUCTION REGION AFTER EARTHQUAKE}

\section{A. Basic Requirement of the Residential Houses After the Earthquake}

1) Requirement of the basic residential houses: Nowadays, people's first demand for residential houses is the house type, one room and one hall, two rooms and one hall, three rooms and one hall, or four rooms and two halls and etc.; the second demand is the area of the residential houses, 60-69m2, 70$79 \mathrm{~m} 2,80-89 \mathrm{~m} 2,90-99 \mathrm{~m} 2,100-110 \mathrm{~m} 2$, larger than $110 \mathrm{~m} 2$; the third demand is the classification of the residential houses: high-rise, small high-rise, multi-storey (with elevator), multistorey (without elevator) and so on; the fourth demand is the price of the residential house, and then the direction, environment of the surrounding, life facilities and so on.

2) Specialty of the reconstruction after the earthquake: The earthquake-stricken zone will face many difficulties. Both in building materials and construction force is need from external input. In the case of victims "homeless", reconstruction after the earthquake can only meet the living problem of the residents, and cannot meet demand for residential building character. And the affected people don't have the right to choose model, size, and etc. like ordinary people to buy commercial housing. The traditional construction technology of the residents is relatively complex, with large energy consumption, longer construction period, relatively single form, small variability, and difficult to meet the demand of diversification of the house, and it is hard to realize the sustainable development of residential house.
3) Basic requirements of the residential houses after the earthquake: The construction speed of the reconstruction after the earthquake is slow, and a considerable number of affected people have to live in resettlement houses for a long period. Therefore, the most important issue is to solve the housing problem of the affected people; modular building can quickly solve the living problem of the affected people. People's psychology after the earthquake is relatively fragile. The main concern of them is the seismic performance of residential buildings. The modular houses are strong in anti-seismic performance, and they are very good against fire, cold and fire; the second is the basic function that the house satisfies. The modular house will be divided into different spaces within the module according to different functional requirements of the house, and different facilities will be assembled according to the requirements (it is equivalent to equip with the necessary facilities for life in the box). All modules will be transported to the destination and hoisted by hoisting equipment after the factory has finished prefabricating; then as for area of the residential houses, modular buildings can be combined into large area because they are prefabricated buildings. Finally the most important point is to satisfy the various requirements of the residents for the residential houses.

\section{B. Basic Combination of the Modular Residential Houses in the Reconstruction Area After the Earthquake}

1) Main member in of the modular buildings ----- boxbuilding: Box building is the most widely used and the most classic design form in the modular building system. The cube box, with its concise line, meets all the conditions of the above mentioned modules, and caters the trend of the straight line development of the building outline at the same time to closely combine the function space and the external frame. Box-buildings are box-like modular components that are prefabricated from reinforced concrete, aluminum, wood, fiberglass, plastics and so on. The box is the box type modular construction of the box building, which is composed of roof, ground and four walls as a hexahedron (it is also made of pentahedron and tetrahedron). Its shape is like a box, thus it is called "box component", also called three-dimensional components, space components and cabin component.

2) Combination forms of the modules: Modular building combination is convenient but not monotonous. By analyzing the existing cases of modular construction, it is not difficult to see that the combination forms of modules are varied. Though it seems a complex architect problem, we can simplify the complex problems from the perspective of design, the way of which is to express all modular combination of the buildings through the relationships between two modules.

There is a certain combination form between the two modules, that is, when the two modules are combined, apart from the contract surface, a large module can be formed in "Fig. 8". 


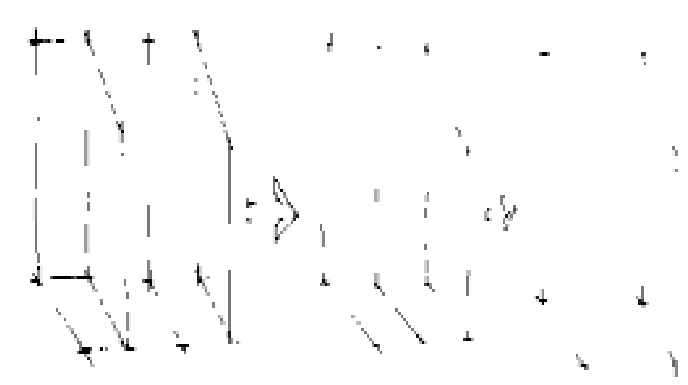

Fig. 8. Combination relationships, self-painted.

There are several combination forms when don't consider the changes between the two modules in "Fig. 9".

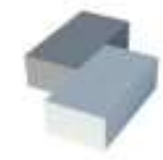

Tangential dislocation

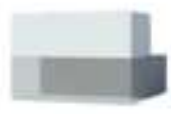

Upright (with the help of auxiliary space)

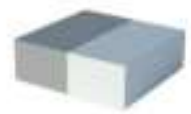

Horizontal doublication

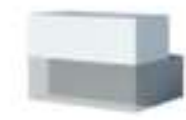

Dislocated (with the help of auxiliary space)

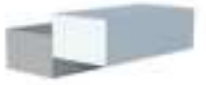

Vertical slide (with the help of auxiliary space)

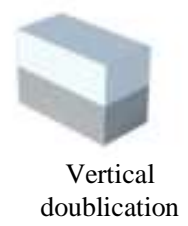

Fig. 9. Combination forms between the two modules, self-painted.

3) Basic combination of the residential houses before the earthquake: Before the earthquake, many villagers can build the houses, which meet their requirements in a relatively low cost, and most of them would adopt the form of "detached houses", which has the independent function for use and independent personality and vitality; though the neighborhood is very close, there would be certain distance among the buildings. These are all the habits of self-privacy that have long been formed in rural areas, and they are also based on respect for neighborhood relationships. Of course, these are cases when the rural residential land is abundant in "Fig. 10".

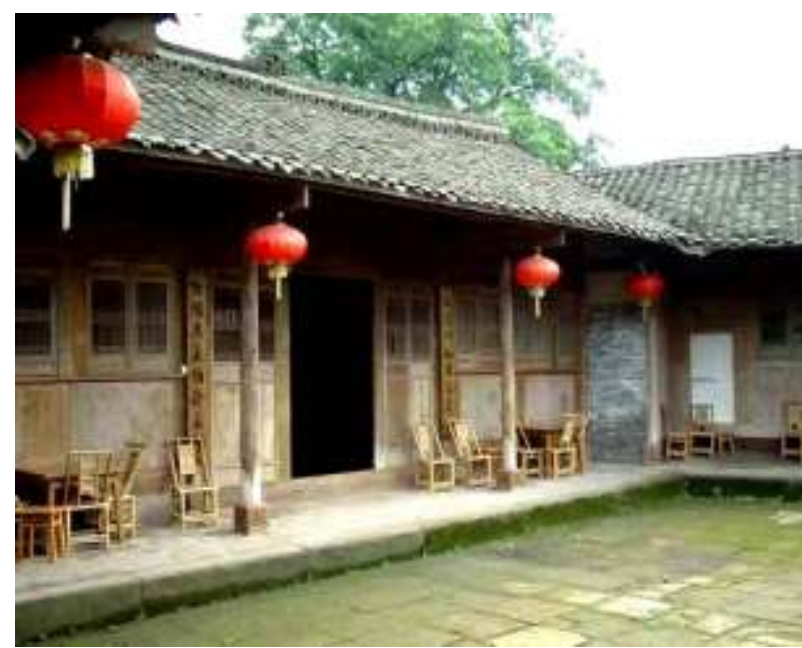

Fig. 10. Residential forms before the earthquake, Source: Baidu picture.

4) The basic combination of modular residential house after earthquake: It is insufficient of the reconstruction land after the earthquake, and it is difficult to keep "detached houses" or holding the around area of the residential houses. Therefore, with the courtyard as the center, several residential houses around it form a semi-open residential community. In this form, it not only solves the problem of insufficient reconstruction land, but also releases the panic after the earthquake of residents. Meanwhile the residents can also take after each other and strengthen the mutual assistance awareness and sense of community; besides, there are also townhouse, single- family type, and semidetached type and so on. All the new houses are consistent of structure and appearance, no change, tidy and clean, and the layout of the inner houses can be summarized by the general appearance in "Fig. 11".

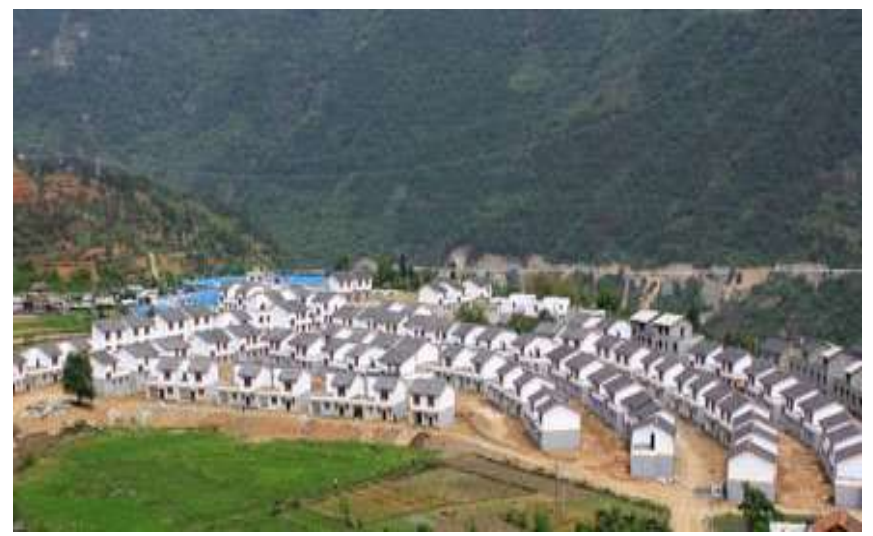

Fig. 11. Songlin Village, Xianfeng Town, Shimian County, Wenchuan, Source: Baidu picture. 


\section{The Countermeasures for the Self-definition Combination of Different Applicable Regions}

1) Combination approach to regional differences between rural and urban areas

a) Combination method of modular housing in rural areas: Because the most family in rural area mainly depend on farming and doing small business and most of them are detached houses. Unlike the urban residence with the form of storey structure, the household in rural area is divided into two main forms; the first one is a residence like quadrangle dwellings, with rooms around the three sides, the courtyard standing in the middle. Besides, each space is very independent, there is no connection among these spaces and the only public space is the courtyard; the second one is a simple quadrilateral building, the inner space of which is divided into different use space. Therefore, this form of modular residence in this area is also relatively independent; first a courtyard is needed to meet the residents' requirement for public space, then the building can be a two storey one because the requirement of storage space for the rural area is larger. The roof is an open one to provide space for residence to grow flowers and grass, dry things and so on.

b) Combination method of modular housing in urban areas: Each set of household is made up of rooms with various functions, each of which has a reasonable size, and it is the basic guarantee of the reasonable size of each kind of room for the household design of different requirements. This paper summarizes the mainstream of high-level products in the current market: the reasonable size of three kinds of household design of "economy", "comfortable", "enjoy type", and the classification of the mainstream high-level products in "Table I" in the current market.

TABLE I. DEMAND COMPARISON OF THE HOUSE AREA

\begin{tabular}{|c|c|c|}
\hline $\begin{array}{l}\text { House Type } \\
\text { Classification }\end{array}$ & House type & Area \\
\hline \multirow{4}{*}{ Economical } & One bedroom, one hall, one toilet & $35-45$ \\
\hline & Two bedrooms, one hall, one toilet & $55-75$ \\
\hline & Four bedrooms, two halls, two toilets & $75-95$ \\
\hline & Two bedrooms, two halls, two toilets & $110-120$ \\
\hline \multirow{3}{*}{ Comfort able } & Three bedrooms, two halls, two toilets & $85-95$ \\
\hline & Three bedrooms, two halls, two toilets & $120-130$ \\
\hline & Four bedrooms, two halls, two toilets & $140-160$ \\
\hline \multirow{3}{*}{ Enjoyable } & $\begin{array}{l}\text { Three bedrooms, two halls, one work room, } \\
\text { three toilets }\end{array}$ & $150-180$ \\
\hline & $\begin{array}{l}\text { Four bedrooms, two halls, one work room, } \\
\text { three toilets }\end{array}$ & $180-200$ \\
\hline & $\begin{array}{l}\text { Five bedrooms, two halls, one work room, } \\
\text { three toilets }\end{array}$ & $220-240$ \\
\hline
\end{tabular}

Residential buildings in urban areas are relatively concentrated and can be built into high-storey. Because of the residents are different, the form of the residence can be diversified; for example, single young entrepreneur, the use area is very small, about $40-50 \mathrm{~m} 2$; the newlyweds need an area of 50-60m2; family of three people need an area of 70$80 \mathrm{~m} 2$.
2) Local specialty requirements for the treatment of combinations

a) Difference of architect in south and north: Climate factor: Northern China is in the middle temperate zone, and it is cold. Because the residents need sufficient sunlight, the buildings mostly face south, with thick walls and roofs to prevent the cold to achieve the result of warm in winter and cool in summer; southern China is hot, most buildings there face south or southeast, and the walls and roofs of residential buildings are light and thin; meanwhile the wall of the bedroom is taller, the front and rear doors are open in order to be convenient to ventilation. The buildings usually are two storeys to prevent the moist.

Topographic factor: In northern China, the plain and plateau are widely distributed and the population density is relatively sparse, so most of the buildings are selected in flat areas.

Humanity factor: The difference in architectural styles between north and south is mainly because of the gap of cultural customs, aesthetic concepts, preferences and etc. between the north and the south. The structure of the northern architecture is simple, and the south is complicated by various factors, just as the saying that "luxury south and servant north", and "complicated south and simple north".

b) Diversity of the room layout caused by the difference in the areas: In the rural areas, the living room is generally called "central room", as the entire family activities center, occupying a very important position in the layout, and requiring a broad space, setting out little furniture and leaving the rest space for activities. In the north rural areas, the width of the central room is usually 3.3 or $3.6 \mathrm{~m}$, depth of 3.9 or $4.2 \mathrm{~m}$, building area of about $12-16 \mathrm{~m} 2$; while in the north area, the width of the central room is usually 3.6 or $3.9 \mathrm{~m}$, depth of $4.8,5.4$ or $6.6 \mathrm{~m}$.

In terms of bedrooms, they are generally around the hall, and avoid interspersing bedroom with bedroom as much as possible.

The kitchen is generally divided into 2 kinds of layout: one is combined with other rooms and convenient to use. Many kitchens in the south are arranged in the wing, and in the north and north China, the kitchen is connected to the bedroom; the other one is to build independently in the courtyard to avoid the smoke entering the living room, but the disadvantage is inconvenient in rainy and snowy days.

As for the main use space in the room, the clear height of bedroom and living room is no less than $2.4 \mathrm{~m}$, partial (the area is no more than $1 / 3$ of the indoor area) height is no less than $2.1 \mathrm{~m}$, and the clear distance of the lower surface of the cross drainage tube and floor and ground in kitchen, bathroom is no less than $1.9 \mathrm{~m}^{1}$

Due to the requirement of life and production in rural area, the storage capacity is large, so it is necessary to consider the storage house, or use the space under the stairs to solve the storage problems. 
Courtyard is an important component of the rural houses, in which you can raise livestocks, plant vegetables and flowers, dry clothes, etc. to create a good living environment. Generally, there are front yard, backyard, front and back yards, etc., what kind of the yard should be considered according to the economic conditions, natural conditions, local conditions and so on. Generally speaking, Sichuan is humid and with less wind, farmers there usually like an open environment and do not build walls, but northerners are used to building walls.

c) The countermeasures for the self-definition combination of different applicable regions: According to different applicable regions, houses in different area can be adjusted by local characteristics, habit, orientation and climatic factors. Take full account of the characteristics of the region for customization and the rural areas can be constructed in the distribution form of enclosures, attached, bi level and etc. Such as urban area, taking single youth as an example, the required space is small, so it is possible to prefabricate a reasonable cuboid module, and add another small module used for bathroom, which is entirely enough. The cuboid module, not only used as a single apartment, but also a living room with a large area, and the small module can also be used as a kitchen.

\section{STUdy ON THE COMBINATION OF MONOMERS COMPOSED OF UNIT COMBINATION}

\section{A. Connection Mode of Composite Unit (Combination Mode)}

The combination of houses in each household is considered as each combination unit, and each combination unit constitutes a building monomer. Each unit body and unit bodies can create a diversified spatial form through a different arrangement and combination. The main building unit combinations are as follows: juxtaposition, zonal, adjacency, distributed, net format, agglomerative, staggered and bi level. The common ones are juxtaposition, adjacency, distributed, net format, agglomerative, staggered and bi level in "Fig. 12".

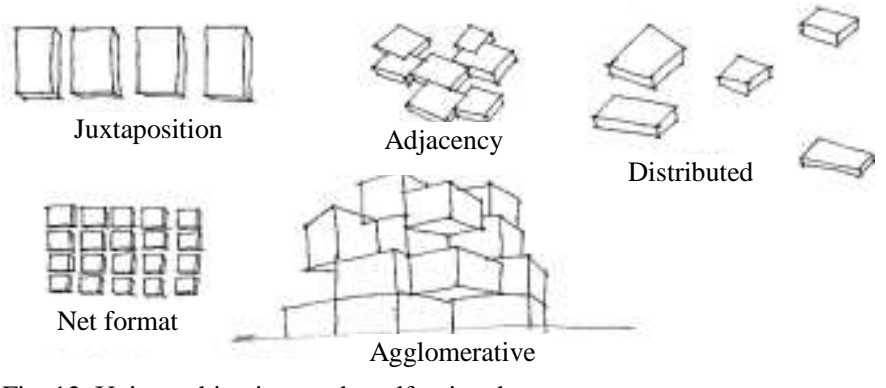

Fig. 12. Unit combination mode, self-painted.

\section{B. Standard Module}

Considering that the fastest way to the reconstruction is the frame structure, with non-load-bearing wall for the enclosure structure. Exterior skin of the wall can be chosen according to the need, the exterior thickness of concrete prefabricated wall is $150 \mathrm{~mm}$, and the inner thickness of concrete prefabricated wall is $120 \mathrm{~mm}$. When the module is combined, the space joints share a wall or remove the wall.
The main spatial classification includes the following three types:

- It is basic plane space of $9000 \times 4800 \mathrm{~mm}$ that can increase or decrease the amount of module according to family use. It is equipped with three types of $3 \mathrm{~m}$, $3.6 \mathrm{~m}, 4.2 \mathrm{~m}$ to meet the height requirements of different space, which can be used as a single apartment, living room and dining room. The size of the wall module is $600 * 3000 \mathrm{~mm} / 3600 \mathrm{~mm} / 4200 \mathrm{~mm}$, and $600 * 2400 \mathrm{~mm}$ of the floor module.

- It is basic plane space of $4200 \times 4800 \mathrm{~mm}$ that can increase or decrease the amount of module according to family use, equipped with three types of $3 \mathrm{~m}, 3.6 \mathrm{~m}$, $4.2 \mathrm{~m}$ of the height, used as a bedroom, study, storeroom. The size of the wall module is $600 * 3000 \mathrm{~mm} / 3600 \mathrm{~mm} / 4200 \mathrm{~mm}$, and $600 * 2400 \mathrm{~mm}$ of the floor module.

- It is basic plane space of $3000 \times 2400 \mathrm{~mm}$ that can increase or decrease the amount of module according to family use, equipped with three types of $3 \mathrm{~m}, 3.6 \mathrm{~m}$, $4.2 \mathrm{~m}$ of the height, used as a bathroom, kitchen and auxiliary space. The size of the wall module is $600 * 3000 \mathrm{~mm} / 3600 \mathrm{~mm} / 4200 \mathrm{~mm}$, and $600 * 2400 \mathrm{~mm}$ of the floor module.

Except for the above use space, if multiple units are combined to form an apartment building, the auxiliary space is required for connection, with main auxiliary space of traffic space, including the following two traffic modules:

1) Horizontal traffic space: According to the requirements in Code for fire protection design of buildings ${ }^{2}$, the corridor width is $1.5 \mathrm{~m}$, with standard corridor floor of $600 * 1500 \mathrm{~mm}$, he wall module of $600 * 3000 / 3600 / 4200 \mathrm{~mm}$, corridor length of $600 \mathrm{~mm}$ multiple.

2) Vertical traffic space: According to the requirements in Design of civil buildings ${ }^{3}$, staircase is prefabricated for double running staircase, with step width of $250 \mathrm{~mm}$, height of $150 \mathrm{~mm}$, bench width of $1.5 \mathrm{~m}$, and slow platform width of $1.5 \mathrm{~m}$. Referring to different wall height, the number of steps is 20, 24, and 28, with stairwell area of $3000 * 4000 \mathrm{~mm} / 4500 / 4800 \mathrm{~mm}$, the wall module of $600 * 3000 / 3600 / 4200 \mathrm{~mm}$.

3) Doors and windows: According to Residential Design Code $^{4}$, shared external door and entrance door is $1.2 * 2.2 \mathrm{~m}$, doors of living room, bedroom and kitchen are $0.9 * 2 \mathrm{~m}$, width of bathroom, balcony (single door) is $0.7 * 2.0 \mathrm{~m}$; window of bedroom, living room and kitchen is $1.2 * 1.5 \mathrm{~m}$, the lower edge of the window is $0.6 \mathrm{~m}$ from the ground, higher edge of the window is $2.1 \mathrm{~m}$. Except for the above size, users can choose the glass curtain wall or french window form to replace the traditional doors and windows. In the process of

Code for Fire Protection Design of Buildings GB50016-2014

Code for Design of Civil Buildings GB50352-2005

Design Code for Residential Buildings GB50096-2011 
prefabricating the wall module, reserve the door and window openings.

\section{User Customization of Spatial Modules}

Based on the standard size of provided living room, bedroom, dining room and bathroom, combined the module of wall and floor module, users can choose to increase or decrease the size of the plane space, the indoor height, the combination mode of the space, etc. according to the population, preferences, habits of the family, actively enter into the design and achieve the diversification of combination mode.
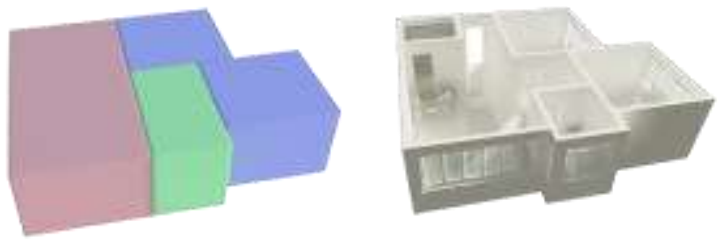

Fig. 13. Two bedrooms and one hall combination mode A, self-painted.
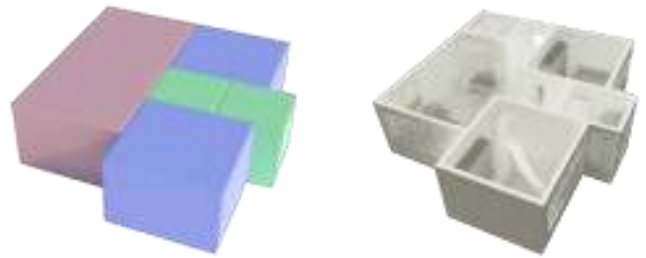

Fig. 14. Two bedrooms and one hall combination mode B, self-painted.
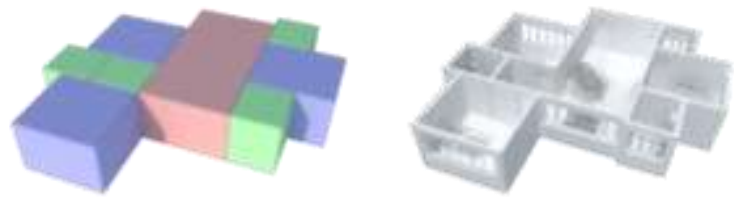

Fig. 15. Three bedrooms and one hall combination mode A, self-painted.
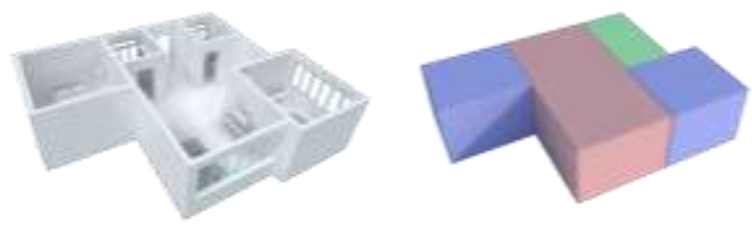

Fig. 16. Three bedrooms and one hall combination mode B, self-painted.
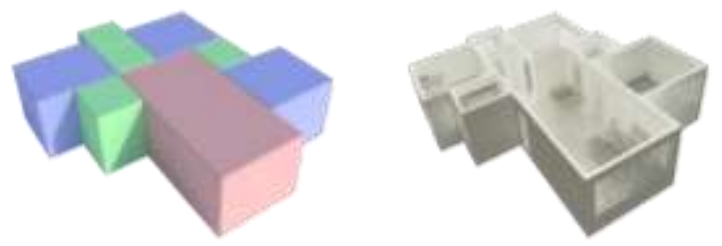

Fig. 17. Three bedrooms and one hall combination mode C, self-painted.
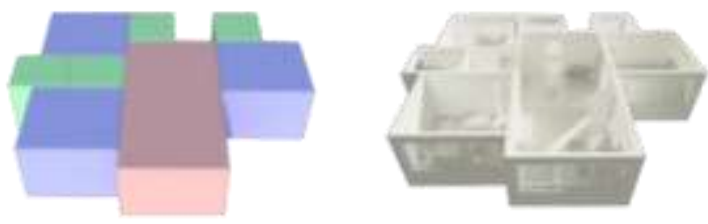

Fig. 18. Three bedrooms and one hall combination mode D, self-painted.

\section{Modular House Design Practice}

\section{A. Design Explanation}

The research in this paper mainly aims at providing modular buildings with various combinations in postearthquake reconstruction applications that can be customized by users. Therefore, it can be applied to common postearthquake regional reconstruction.

\section{B. Design Application}

Perform 5 different combinations of design by using the above-mentioned basic modules of various building components:

1. Rotation combination mode in "Fig. 19".

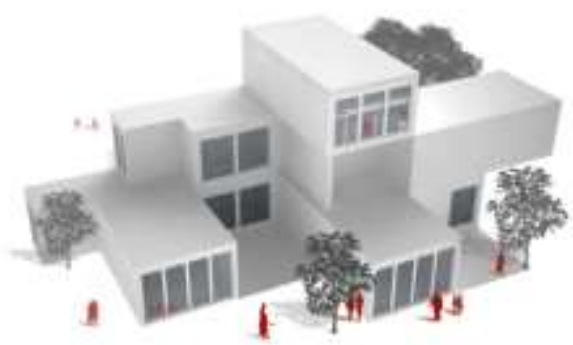

Fig. 19. Rotation combination mode, self-painted.

2. Overlapping combination mode "Fig. 20".

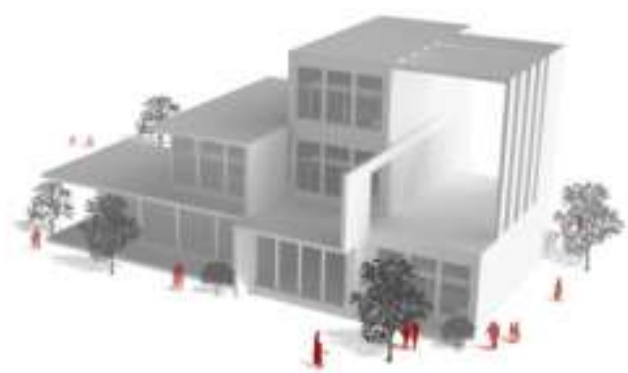

Fig. 20. Overlapping combination mode, self-painted.

3. Staggered combination mode "Fig. 21". 


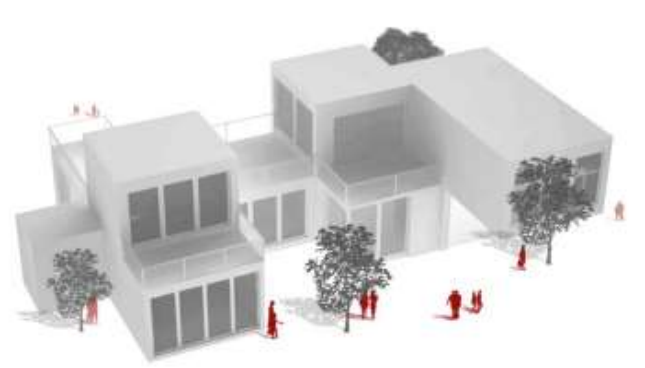

Fig. 21. Staggered combination mode, self-painted.

4. Agglomeration combination mode in "Fig. 22".

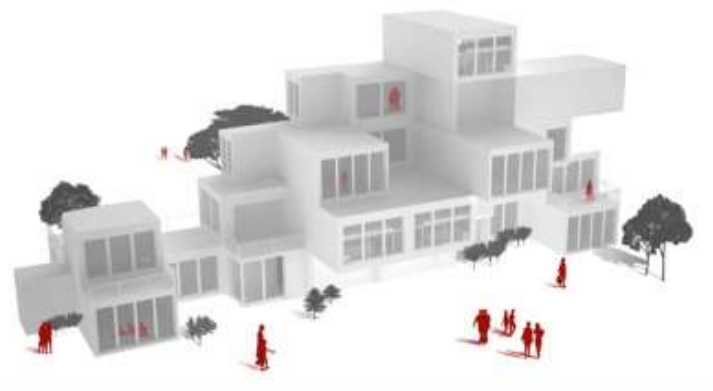

Fig. 22. Agglomeration combination mode, self-painted.

5. Coincidence method in 'Fig. 23"

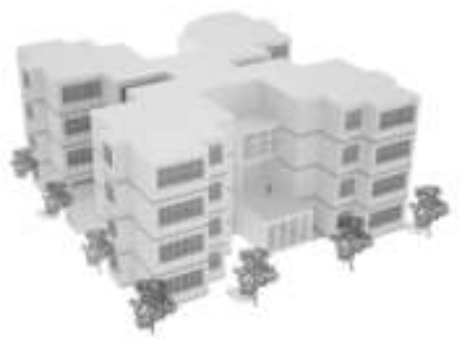

Fig. 23. Coincidence mode, self-painted.

"User-defined" includes the following two aspects in the actual application process:

1) Monomer space usage area customization: Due to the diversity of module functions, users can make the transformation of spatial function according to their own needs. If users think that the use space of the standard bedroom cannot meet the needs, they can increase or decrease their own wall and floor unit modules, provide larger use space to meet the residents' requirements.

2) Combined space quantity and form customization: Take a single young male as an example, a single apartment consisting of $9000 \times 4800 \mathrm{~mm}$ living space and $3000 * 2400 \mathrm{~mm}$ bathroom space. When the resident gets married and has children, and the original use space cannot meet the needs for use, he can again increase the other use space, but the feasibility of overall increase and decrease of such space modules need to be taken into consideration.

\section{CONCLUSION}

This paper innovatively puts forward the "User-defined Design Study of Modular Houses", mainly elaborating the combination of modules, that is, the two modules that remove the contact surface are overlapped, the combination of transportation space is not required, and the combination of transportation space is required, and meanwhile five combinations of building monomers are proposed. Based on this, the paper discusses the user-defined content, namely the monomer space usage area customization and combined space quantity and form customization. Through detailed analysis and research, this paper introduces the advantages of modular construction in each aspect, modular construction with its convenient, quick, economic and other characteristic by the public recognition; modular architecture is used in the reconstruction to solve the problems existing in the reconstruction.

\section{REFERENCES}

[1] Tong Feifei, Modular inquiry of architectural design [D]. Zhengzhou University 2013-5 全非非,建筑设计的模块化探究[D]. 郑州大学 2013-5

[2] Xue Shasha, The application of modular thought in modern residential design [D]. Beijing University of Civil Engineering and Architecture 2013-6 薛莎莎,模块化思想在现代住宅设计中的运用[D].北京建筑 大学 2013-6

[3] Hu Zhibin Wang Yanfeng, Modular building design features and operability [J]. Knowledge economy 2010-08-01, (16):120 胡志斌 王 彦峰, 模块化建筑的设计特点及可操作性 [J]. 知识经济 2010-0801,(16):120

[4] Qu Yuanyuan, Development and research of modular space design [D]. Suzhou University 2009-03 曲媛媛,模块化空间设计的发展与研究 [D].苏州大学 2009-03

[5] Lin Rong, On unit integration of buildings [D]. Tianjin University 2005-06 林嵘,论建筑单元体整合[D].天津大学 2005-06

[6] Chen Haifeng, Study on the reconstruction strategy of rural settlements after the earthquake of 512 [D]. Southwest Jiaotong University 2009-12 陈海峰, 512 地震后乡村聚落空间重构策略的研究[D].西南交通大学 2009-12

[7] Han Xiaolong, Post-disaster reconstruction of architecture response [D] Shandong University of Architecture 2012-5 韩晓龙, 灾后重建的建 筑学应答[D].山东建筑大学 2012-5

[8] Wang Yina, Research on Renovation Model of Production-Life Space in Village Reconstruction after Earthquake [D]. Tianjin University School of Architecture 2012-6 王懿娜, 震后重建中村落生产-生活空 间的整治模式研究[D].天津大学建筑学院 2012-6

[9] Sun Jian, Modular design of space reorganization and integration [J]. Art-Science-Technology 2013-2, (39):10 孙䇝,空间重组与整合的模 块化设计 [J].艺术科技 2013-2,(39):10

[10] Xu Jianhe, The generation of space - from the unit body to the group structure [J]. Huazhong Construction 2006-05, (24):26-30 许建和,空间 的生成一从单元体到群构 [J]. 华中建筑 2006-05,(24):26-30

[11] Pan Huiyu Zhou Wei, Practice and thinking on the construction of economical and practical green residential buildings in quake-hit areas of sichuan province $[\mathrm{J}]$. Proceedings of the international conference on building environmental science and technology, 2010 2010-05-07 10071011 潘慧宇 周伟,四川地震灾区经济实用绿色民居建设的实践与思 考[J]. 2010 年建筑环境科学与技术国际学术会议论文集 2010-05-07 1007-1011 
[12] Hu Zhibin, Wang Yanfeng, Modular building design features and operability [J]. Knowledge economy 2010-08-01, (16):120 胡志斌王 彦峰, 模块化建筑的设计特点及可操作性 [J]. 知识经济 2010-0801,(16): 120

[13] Zeng Xiuxia, Designer's post-disaster building plan [J]. Architectural life 2008-07 78-83 曾秀霞, 设计师的灾后建筑方案 [J]. 建筑生活 2008-07 78-83

[14] Huo Ziwen, Guo Wei, etc. Practice and thinking of village planning under the background of post-quake reconstruction in Yushu [J]. Jiangxi Journal of Agricultural Sciences 2011, 23 (6): 143-147 霍子文 郭伟等, 玉树地震灾后重建背景下村庄规划的实践与思考[J].江西农业学报 2011,23(6):143-147

[15] Bridge Vranckx Modern Interiors Design Source [M].Collins Design, 2007.

[16] Sandu Color and space [M].Britain: SANDU, 2013.

[17] Phoenix Garden Structure [M].Britain phoenix publishing ,2012. 